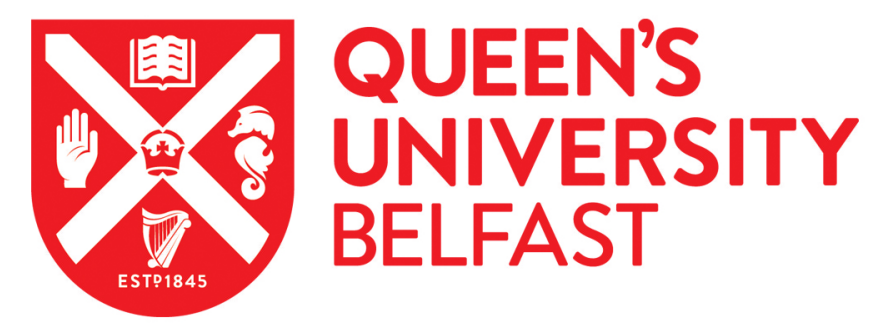

\title{
Skin Cancer trends in Northern Ireland and consequences for provision of dermatology services
}

Hoey, E., Devereux, C. E. J., Murray, L., Catney, D., Gavin, A., Kumar, S., Donnelly, D., \& Dolan, O. M. (2007). Skin Cancer trends in Northern Ireland and consequences for provision of dermatology services. British Journal of Dermatology, 156(6), 1301-1307. https://doi.org/10.1111/j.1365-2133.2007.07936.x

\section{Published in:}

British Journal of Dermatology

Queen's University Belfast - Research Portal:

Link to publication record in Queen's University Belfast Research Portal

\section{General rights}

Copyright for the publications made accessible via the Queen's University Belfast Research Portal is retained by the author(s) and / or other copyright owners and it is a condition of accessing these publications that users recognise and abide by the legal requirements associated with these rights.

Take down policy

The Research Portal is Queen's institutional repository that provides access to Queen's research output. Every effort has been made to ensure that content in the Research Portal does not infringe any person's rights, or applicable UK laws. If you discover content in the Research Portal that you believe breaches copyright or violates any law, please contact openaccess@qub.ac.uk. 


\title{
Skin cancer trends in Northern Ireland and consequences for provision of dermatology services
}

\author{
S.E.H. Hoey, C.E.J. Devereux, L. Murray, ${ }^{\star}$ D. Catney, $\dagger$ A. Gavin, $\dagger$ S. Kumar, ${ }^{\star}$ D. Donnelly $\dagger$ and O.M. Dolan
}

Department of Dermatology, Royal Group of Hospitals, Belfast BT12 6BA, U.K.

*Department of Epidemiology, Queen's University Belfast, Belfast, U.K.

$\dagger$ Northern Ireland Cancer Registry, Belfast, U.K.

\section{Summary}

\section{Correspondence}

Susannah Hoey.

E-mail: hoeysusannah@hotmail.com

Accepted for publication

25 January 2007

Key words

basal cell carcinoma, epidemiology, malignant

melanoma, squamous cell carcinoma, workload

Conflicts of interest

None declared.
Background The incidence of skin cancer, both melanoma and nonmelanoma skin cancer (NMSC), is rising throughout the world. The evaluation of trends in skin cancer will allow better planning of the future development of skin cancer services.

Objectives Using data collected from the Northern Ireland Cancer Registry (NICR), the incidence of the three major cutaneous cancers, basal cell carcinoma (BCC), squamous cell carcinoma (SCC) and malignant melanoma (MM), was determined and the workload associated with their management assessed.

Methods The records of patients with a first diagnosis of BCC, SCC or MM occurring between 1993 and 2002 were retrieved from the NICR database. The annual age- and sex-adjusted incidence rates of all three skin cancers were computed per 100000 person-years by direct standardization according to the European Standard Population. Trends in incidence were estimated by calculating the estimated annual percentage change using Microsoft Excel. For patients registered with the NICR as having BCC, SCC or MM, the number of pathological reports where malignant samples had been examined was counted and then summed to provide the number of specimens examined each year between 1993 and 2004.

Results For all three cancers the age-specific rates for both males and females increased with age, except for MM in men aged 75 years and over, where the rates were seen to decrease. Over the 12-year period there was a $62 \%$ increase in the overall number of skin cancer samples processed by local pathology laboratories and a 20\% increase in the number of patients. These data highlight the fact that many patients will have more than one skin cancer, which reinforces the benefit in collecting data for both patient and sample numbers in order to obtain a true reflection of the workload. The data have also shown that more affluent men and women have higher rates of BCC and MM than their less affluent counterparts.

Conclusions In view of the data presented it is clear that management of NMSC and MM will impose significant demands on services in the years ahead. This will impact on the entire multidisciplinary team. Future planning, in terms of manpower and resources, will prove essential if we are to remain in a position to manage our patients with these malignant tumours appropriately.
The incidence of skin cancer, both melanoma and nonmelanoma skin cancer (NMSC), is rising throughout the world, with NMSC being the most common of all cancers. ${ }^{1-5}$ Increased resources, both in terms of personnel and of finance, will be required to meet the demands that the management of these tumours will place on health services. The recently published U.K. National Institute for Health and Clin- ical Excellence consultation document on skin tumours has recommended that the epidemiology of skin cancer is studied further. ${ }^{5}$ By evaluating the trends in skin cancer we will be in a better position to plan the future development of skin cancer services. However, few U.K. cancer registries routinely collect complete data on NMSC. ${ }^{6}$ In this paper, using data collected by the Northern Ireland Cancer Registry (NICR) since 1993, 
we examine the epidemiology of skin cancers, including recent trends in incidence and health service workload. These data will help inform the future development of appropriate skin cancer services.

\section{Materials and methods}

The NICR is a population-based cancer registry that electronically collects data on cancer from all hospital administration systems and pathology laboratories within the province. For registration purposes patients with pathologically confirmed NMSC are registered by the NICR according to the European Network of Cancer Registries ${ }^{7}$ guidelines for registration of NMSC, which recommend that only the first occurrence of an NMSC is registered. However, the Registry holds data on each pathology report relating to individuals with skin cancer. Version 10 of the International Classification of Diseases was used to identify NICR registrations of NMSC (C44) and malignant melanoma (MM) (C43). NMSC cases registered with SNOMED codes between 80903 and 80953 were considered as basal cell carcinoma (BCC) while those with SNOMED codes 80703 or 80713 were considered as squamous cell carcinoma (SCC).

The records of 14500 patients with a first diagnosis of BCC and of 6405 patients with a first diagnosis of SCC occurring between 1993 and 2002 were retrieved from the NICR database. Of the 14500 patients with BCC extracted, 58 were excluded from subsequent analyses: 57 diagnosed outside Northern Ireland and one diagnosed after the age of 100 years. Four patients with SCC were excluded because they were diagnosed after the age of 100 years. Of the 1866 patients with MM registered with the NICR during the same period, none was excluded from the subsequent analysis.

The annual age- and sex-adjusted incidence rates of $\mathrm{MM}$ and NMSC were computed per 100000 person-years by direct standardization according to the European Standard Population (European age-standardized rates, EASRs). Trends in incidence were estimated by calculating the estimated annual percentage change (EAPC), using Microsoft Excel. The EAPC was calculated by fitting a regression line to the natural logarithm of the incidence rates, using calendar year as a regression variable, i.e. $y=m x+b$, where $y=\ln ($ rate $)$ and $x=$ calendar year. Then the EAPC $=100 *\left(e^{m}-1\right)$. This calculation assumes that the rates increased or decreased at a constant rate over the period examined. Joinpoint ${ }^{8,9}$ analyses were performed to discern significant changes in the trend and, if present, the time-point at which they occurred. Joinpoint connects linear segments on a log/linear scale, to identify changes (significant or otherwise) in trend data, in terms of annual rates of change, in fixed periods of time. The program was also employed to investigate socioeconomic trends in incidence, using EASRs calculated by deprivation quintile and sex. Patients were assigned a deprivation quintile using the 2001 Northern Ireland Noble economic deprivation measure which assigned a deprivation score to each Census Enumeration District (ED) in Northern Ireland based upon the economic characteristics of all persons usually resident in that area. ${ }^{10}$ For the purposes of this study the EDs were ranked according to this score and divided into quintiles, with quintile 1 containing the fifth of the population resident in the least deprived EDs and quintile 5 containing the fifth of the population resident the most deprived EDs.

Further to determine the workload associated with skin cancer in Northern Ireland, data on all examinations of malignant histological skin cancer specimens were collated. For patients registered with the NICR as having BCC, SCC or MM, the number of pathological reports where malignant samples had been examined was counted and then summed to provide the number of specimens examined each year between 1993 and 2004 .

\section{Results}

\section{Basal cell carcinoma}

\section{Incidence}

On average, 712 men and 732 women were diagnosed with BCC each year during the study period (1993-2002), accounting for approximately $17 \%$ of both male and female cancers registered with the NICR. The mean annual male and female age-standardized incidences over the period were 94 and 72 per 100000 , respectively, giving a male/female incidence ratio of $1 \cdot 3: 1$. Fifty per cent of BCC cases were diagnosed in men aged 68 years and below and in women aged 71 years and below $(P<0.001)$. Ten per cent of cases occurred in persons (both sexes) aged $<50$ years. Agespecific rates of BCC increased with age for both sexes and levelled off among women aged 80 years or more but continued to rise in men (Fig. 1).

\section{Trends}

Between 1993 and 2002, the age-adjusted incidence rates for BCC increased from 88 to 104 per 100000 in men, and fell in women from 75 to 71 per 100000 . The EAPCs for men and women over this period were $1 \cdot 5 \%$ and $-0 \cdot 6 \%$, respectively (Table 1 ). Joinpoint analysis confirmed a statistically significant increase in incidence in men $(P=0.012)$ but the change in female rates did not reach statistical significance. The observed increase in male rates was driven by the increase in men aged 70 years or over with the disease (Table 1). No trend was evident among men aged 25-49 years or 50-69 years and no trend was evident in any female age group (Table 1).

\section{Deprivation}

There was a statistically significant downward pattern (male $\mathrm{P}=0.010$; female $\mathrm{P}=0.012$ ) in age-standardized incidence of BCC across the quintiles of area-based deprivation score. Men and women living in the most affluent areas had EASRs 


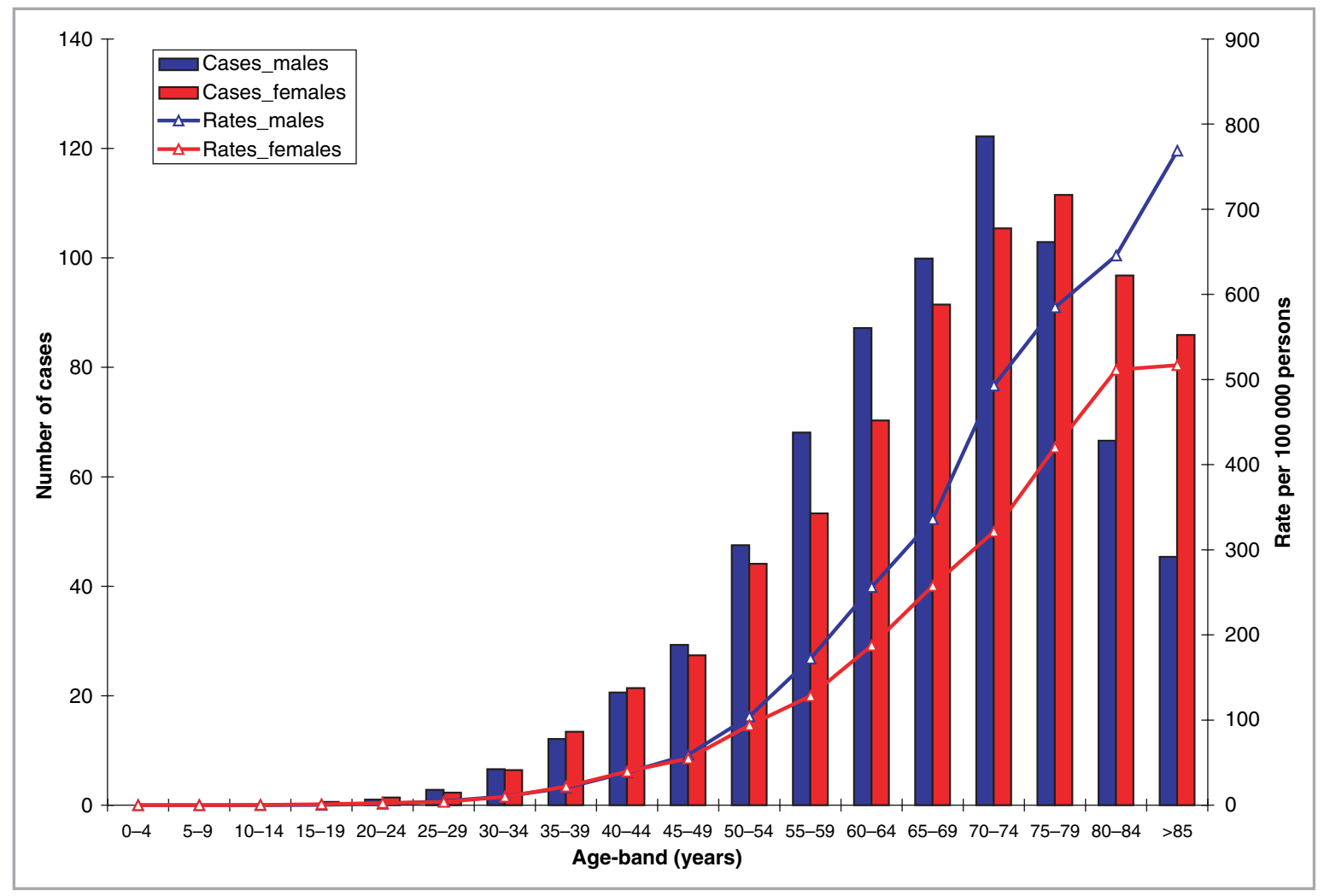

Fig 1. Number of incident cases and age-specific rates of basal cell carcinoma per 100000 persons (averaged over the diagnostic period 1993-2002).

Table 1 Overall and age-specific incidence of basal cell carcinoma (BCC), squamous cell carcinoma (SCC) and malignant melanoma (MM) (per 100000 persons) by sex (1993-2002)

\begin{tabular}{|c|c|c|c|c|}
\hline & \multicolumn{2}{|l|}{ Males } & \multicolumn{2}{|l|}{ Females } \\
\hline & $\operatorname{EAPC}^{\mathrm{a}}(95 \% \mathrm{CI})$ & Incidence $^{\mathrm{b}}$ & $\operatorname{EAPC}^{\mathrm{a}}(95 \% \mathrm{CI})$ & Incidence $^{\mathrm{b}}$ \\
\hline \multicolumn{5}{|l|}{ BCC } \\
\hline All ages & $1.5(0.4-2.5)$ & 94 & $-0 \cdot 6(-1 \cdot 9-0 \cdot 7)$ & 72 \\
\hline $25-49$ years & $0 \cdot 1(-2 \cdot 2-2 \cdot 5)$ & 27 & $0 \cdot 3(-2 \cdot 2-2 \cdot 9)$ & 26 \\
\hline $50-69$ years & $0 \cdot 8(-1 \cdot 1-2 \cdot 6)$ & 199 & $-0 \cdot 9(-2 \cdot 8-1 \cdot 1)$ & 154 \\
\hline $70+$ years & $2 \cdot 5(1 \cdot 1-3 \cdot 8)$ & 579 & $-0 \cdot 6(-2 \cdot 0-0 \cdot 9)$ & 405 \\
\hline \multicolumn{5}{|l|}{ SCC } \\
\hline All ages & $0.6(-0.7-1.9)$ & 46 & $-0 \cdot 2(-1 \cdot 3-0 \cdot 8)$ & 23 \\
\hline 25-49 years & $1 \cdot 5(-6.5-10 \cdot 2)$ & 6 & $-4 \cdot 2(-15 \cdot 3-8 \cdot 4)$ & 4 \\
\hline 50-69 years & $-0 \cdot 8(-3 \cdot 1-1 \cdot 7)$ & 72 & $-0 \cdot 9(-3 \cdot 7-1 \cdot 9)$ & 33 \\
\hline $70+$ years & $1 \cdot 4(0 \cdot 1-2 \cdot 7)$ & 401 & $0 \cdot 6(-1 \cdot 5-2 \cdot 7)$ & 209 \\
\hline \multicolumn{5}{|l|}{$\mathrm{MM}$} \\
\hline All ages & $2 \cdot 8(0 \cdot 2-5 \cdot 6)$ & 10 & $1 \cdot 1(-1 \cdot 8-4 \cdot 0)$ & 13 \\
\hline $25-49$ years & $2 \cdot 2(-4 \cdot 0-8 \cdot 8)$ & 8 & $-1 \cdot 6(-5 \cdot 9-2 \cdot 9)$ & 13 \\
\hline 50-69 years & $0 \cdot 8(-3 \cdot 9-5 \cdot 8)$ & 18 & $3 \cdot 4(-1 \cdot 0-8 \cdot 1)$ & 22 \\
\hline $70+$ years & $5 \cdot 9(1 \cdot 5-10 \cdot 4)$ & 35 & $3 \cdot 6(-1 \cdot 2-8 \cdot 6)$ & 35 \\
\hline
\end{tabular}

${ }^{\mathrm{a} E s t i m a t e d ~ a n n u a l ~ p e r c e n t a g e ~ c h a n g e ~(E A P C) ~ i n ~ i n c i d e n c e ; ~ C I, ~ c o n f i d e n c e ~ i n t e r v a l . ~}{ }^{\mathrm{b}} \mathrm{Mean}$ age-standardized incidence per 100000 persons for the period 1993-2002. of 117 and 85 per 100000 , respectively, while corresponding rates in those living in the most deprived areas were 83 and 66 per 100000 , respectively. When this analysis was restric- ted to diagnoses in two 5-year periods (before and after 1998), this relationship was observed in both periods in men but only in the latter period in women. 


\section{Squamous cell carcinoma}

\section{Incidence}

On average, 357 men and 283 women were diagnosed with SCC each year, accounting for $8 \%$ and $6 \%$ of male and female cancers registered with the NICR, respectively. The mean annual male and female age-standardized incidences over the period were 46 and 23 per 100000 , respectively, giving a male/female incidence ratio of $2: 1$. Fifty per cent of SCC cases were detected in men aged 74 years and below and in women aged 78 years and below $(P<0.001)$. Four per cent of cases occurred in persons (both sexes) aged $<50$ years. Age-specific rates of SCC increased with age for both sexes (Fig. 2). Rates were consistently higher among men than women, with the exception of 35-39-year-olds, where absolute differences were small.

\section{Trends}

Between 1993 and 2002, the age-adjusted incidence rates for SCC increased from 41 to 48 per 100000 in men but remained steady at 22 per 100000 in women. The EAPCs for men and women over this period were $0 \cdot 6 \%$ and $-0 \cdot 2 \%$, respectively (Table 1). Joinpoint analysis did not reveal any statistically significant increase in overall incidence in either sex over the period; however, a significant increase in rates was observed among men aged 70 years and over.

\section{Deprivation}

There was no relationship between area-based deprivation scores and SCC incidence for either sex over the period as a whole or in the two 5-year periods (before and after 1998).

\section{Malignant melanoma}

\section{Incidence}

On average, 72 men and 114 women were diagnosed with MM each year, accounting for $2 \%$ and $3 \%$ of male and female cancers registered with the NICR, respectively. The average annual male and female age-standardized incidences over the period were 10 and 13 per 100000 , respectively, giving a male/female incidence ratio of $0 \cdot 8: 1$. Fifty per cent of MM cases were detected in men aged 58 years and below and in women aged 57 years and below $(P<0 \cdot 05)$. Thirty five per cent of male cases and 39\% of female cases occurred in persons aged $<50$ years. Age-specific rates of MM increased with age in both sexes but not as rapidly as for SCC or BCC (Fig. 3). In contrast to BCC and SCC, female rates were

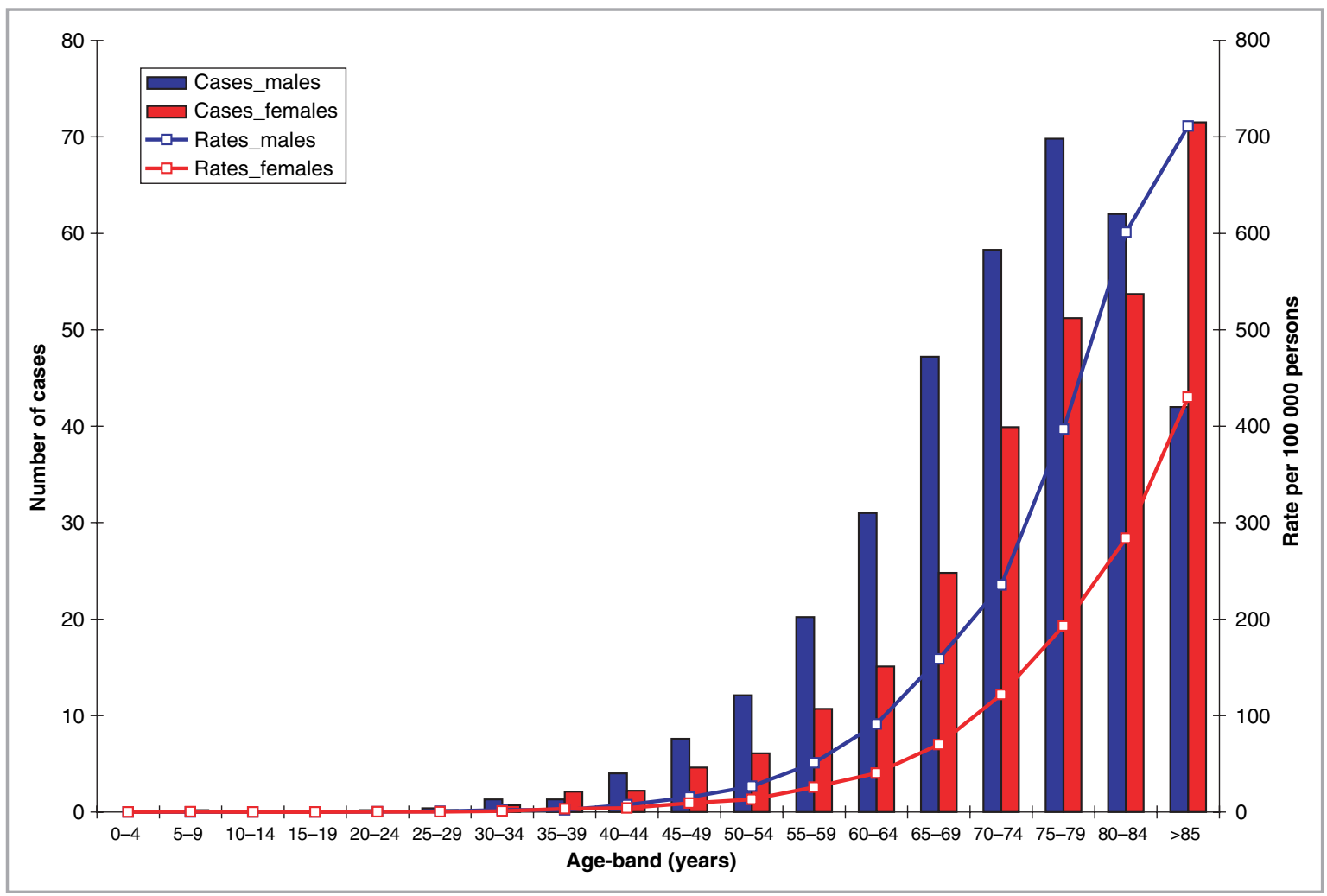

Fig 2. Number of incident cases and age-specific rates of squamous cell carcinoma per 100000 persons (averaged over the diagnostic period 1993-2002). 


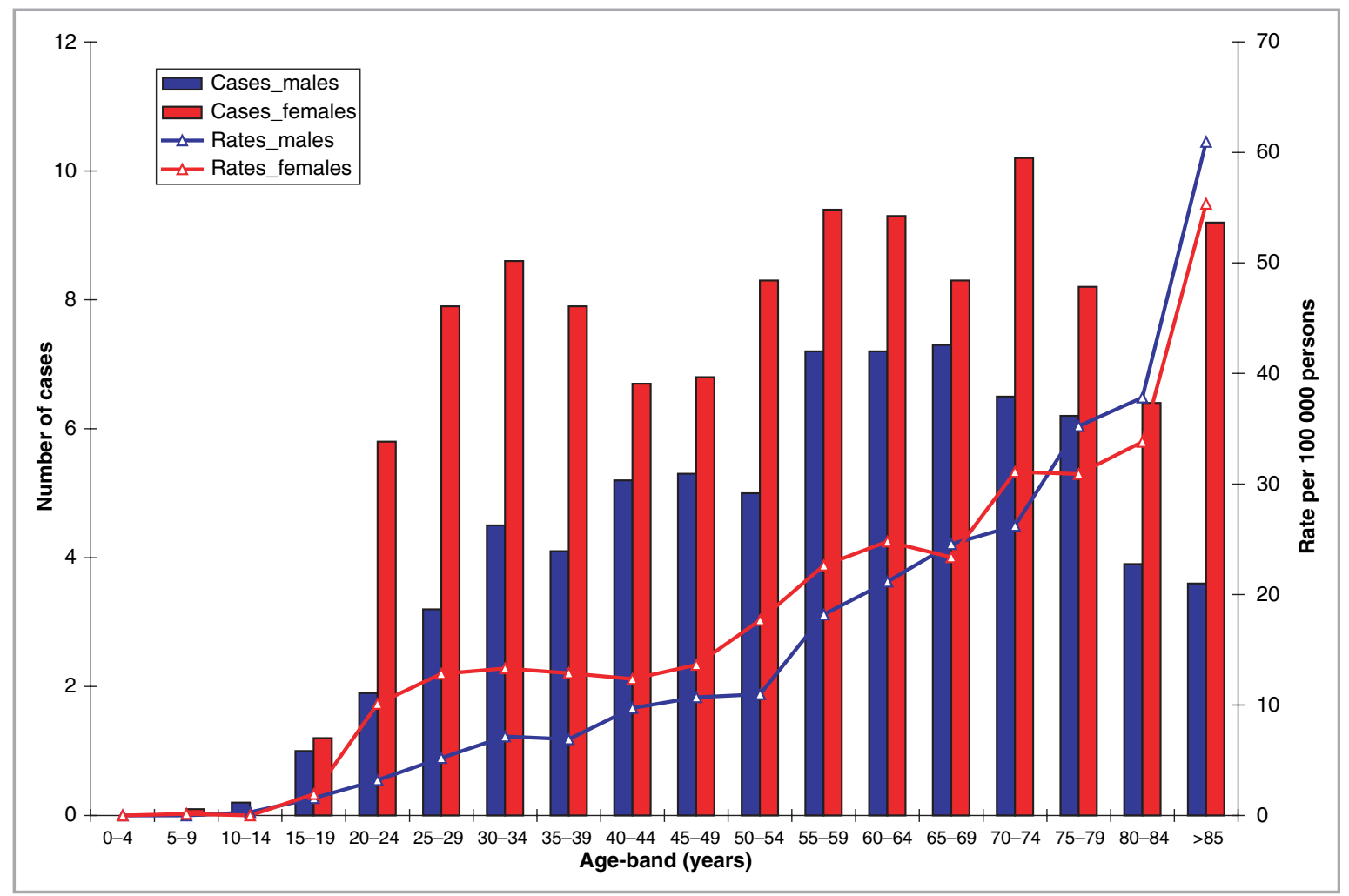

Fig 3. Number of incident cases and age-specific rates of malignant melanoma per 100000 persons (averaged over the diagnostic period 1993-2002).

consistently higher than male rates, with the exception of 65-69-year-olds and persons aged 75 years and over.

\section{Trends}

Between 1993 and 2002, the age-adjusted incidence rates for MM increased from 8 to 12 per 100000 in men and from 14 to 16 per 100000 in women. The EAPCs for men and women over this period were $2 \cdot 8 \%$ and $1 \cdot 1 \%$, respectively (Table 1). Joinpoint analysis detected significant changes in the linear trend for males and females over the period of interest. Male rates increased significantly between 1993 and 1995 ( $\mathrm{P}=0.049)$ and between 1998 and 2002 ( $\mathrm{P}=0.002)$. These observed increases in incidence were associated with an increase in rates among men aged 70 years and over $(\mathrm{P}=$ $0 \cdot 01)$. Small changes in incidence among men aged 2549 years or 50-69 years were not statistically significant. Female rates increased significantly from 1997 onwards ( $\mathrm{P}=$ $0.022)$, driven by marginal increases in rates for 50-69-yearolds $(P=0.07)$ and the elderly $(P=0.08)$.

\section{Deprivation}

There was a strong negative association between quintile of area-based deprivation score (male $\mathrm{P}=0.011$; female $\mathrm{P}<0.001)$ and age-standardized incidence of MM. Men and women living in the most affluent areas had EASRs of 15 and
19 per 100 000, respectively, while corresponding rates in persons living in the most deprived areas were 6 and 8 per 100000 , respectively. The same pattern was observed in both 5-year periods before and after 1998.

\section{Workload}

In total, 26982 BCC, 9370 SCC and 2943 MM histological specimens were examined during this period. This workload data corresponded to actual patient numbers of 17879,7427 and 2351 for BCC, SCC and MM, respectively (Table 2).

\section{Discussion}

Worldwide, few cancer registries routinely collect complete data on skin cancer ${ }^{3}$ and there is considerable variation in registration practice relating to skin cancers within the U.K. ${ }^{6}$ The collection of data on NMSC is often omitted because of the large number of tumours involved and their nonaggressive nature. As a result, robust epidemiological data on NMSC are sparse. ${ }^{3,5}$

Since 1993, the NICR, which uses electronic data capture, has recorded complete data on all pathologically confirmed skin cancers. Using this information, the incidence of these three major cutaneous cancers has been determined and the workload associated with their management assessed. The data are comprehensive for both MM and NMSC and the quality and completeness of the data provide useful epidemiological 
Table 2 Histological specimens and incidence of basal cell carcinoma (BCC), squamous cell carcinoma (SCC) and malignant melanoma (MM) (1993-2004)

\begin{tabular}{|c|c|c|c|c|c|c|c|c|}
\hline & \multicolumn{2}{|l|}{$\mathrm{BCC}$} & \multicolumn{2}{|l|}{ SCC } & \multicolumn{2}{|l|}{ MM } & \multicolumn{2}{|l|}{ Total } \\
\hline & Samples & Patients & Samples & Patients & Samples & Patients & Samples & Patients \\
\hline 1993 & 1784 & 1370 & 636 & 528 & 221 & 182 & 2641 & 2080 \\
\hline 1994 & 1851 & 1349 & 738 & 577 & 218 & 179 & 2807 & 2105 \\
\hline 1995 & 1986 & 1321 & 826 & 603 & 203 & 169 & 3015 & 2093 \\
\hline 1996 & 2126 & 1562 & 728 & 623 & 191 & 175 & 3045 & 2360 \\
\hline 1997 & 2020 & 1467 & 721 & 631 & 196 & 160 & 2937 & 2258 \\
\hline 1998 & 2074 & 1410 & 669 & 594 & 205 & 177 & 2948 & 2181 \\
\hline 1999 & 2260 & 1483 & 768 & 616 & 218 & 180 & 3246 & 2279 \\
\hline 2000 & 2248 & 1524 & 759 & 608 & 233 & 187 & 3240 & 2319 \\
\hline 2001 & 2306 & 1461 & 805 & 641 & 270 & 215 & 3381 & 2317 \\
\hline 2002 & 2621 & 1668 & 864 & 687 & 310 & 247 & 3795 & 2602 \\
\hline 2003 & 2812 & 1714 & 860 & 643 & 301 & 211 & 3973 & 2568 \\
\hline 2004 & 2894 & $1550^{a}$ & 996 & $676^{a}$ & 377 & $269^{a}$ & 4267 & $2495^{\mathrm{a}}$ \\
\hline $\begin{array}{l}\% \text { increase } \\
\qquad(1993-2004)\end{array}$ & 62 & 13 & 57 & 28 & 71 & 48 & 62 & 20 \\
\hline
\end{tabular}

information to assist in service development within the region.

The majority of the population in Northern Ireland has fair skin colour, in keeping with Fitzpatrick skin types I and II. The census in 2001 revealed that the population in Northern Ireland was $1 \cdot 685$ million, constituting $2 \cdot 87 \%$ of the total U.K. population. It was noted that in Northern Ireland ethnic minority groups accounted for $<1 \%$ of the total population. ${ }^{11}$ In comparison, in the same census $87 \%$ of the population of England and $96 \%$ of Wales gave their ethnic origin as white British. ${ }^{12}$ Therefore the population reported in this paper reflects much less variability related to ethnic origin. We acknowledge that the data in this paper may not extrapolate completely to the rest of the U.K., but should be relevant to Scotland where ethnic minority groups account for $2 \%$ of the population. ${ }^{12}$

Over the 10-year period from 1993, the incidence of skin cancer in Northern Ireland has increased. For all three cancers the age-specific rates for both males and females increased with age. There were significant changes in the linear trend of age-adjusted incidence rates for males with $\mathrm{BCC}$ and $\mathrm{MM}$ (Table 1). These figures are similar to previous reports of increasing incidence for both the U.K. and Europe; however, the rates continue to be lower than in the U.S.A. and Australia. ${ }^{3,13-16}$

These data have also shown that more affluent men and women have higher rates of BCC and MM than their less affluent counterparts. No such difference was seen for SCC. This association between affluence and $\mathrm{MM}$ is well recognized ${ }^{17}$ but it has not been previously reported for BCC. It is possible that patients from lower socioeconomic groups do not present for medical care and this may result in some under-reporting of NMSC.

Reporting of skin cancers, in particular NMSC, is limited by the European code of practice which requires that only the first skin cancer is registered for each tumour type. Many patients have more than one NMSC, but these subsequent tumours will not be registered. Thus, skin cancers are subject to significant under-registration. ${ }^{18}$ McLoone et al. reviewed local data from both the NICR and pathology records over a 6 -month period in 1999. They found that the numbers registered officially by the NICR underestimated the true incidence of BCC by 33\% (95\% confidence interval 29-38\%). ${ }^{19}$ This compares with data published by Lucke et al., who report an under-recording of BCC by $31 \%$ in the Greater Glasgow area in 1995. ${ }^{4}$ The incidence figures reported in this paper must be considered in the context of approximately 30\% underreporting.

In order to address the limitations of solely examining the incidence of skin cancer, we also analysed workload by investigating the trends in the numbers of histological specimens obtained from skin cancer patients. This was possible because the NICR records these data. Over the 12-year period examined there was a $62 \%$ increase in the overall number of skin cancer samples processed by local pathology laboratories and a $20 \%$ increase in the number of patients. These data highlight the fact that many patients will have more than one skin cancer, which reinforces the benefit in collecting data for both patient and sample numbers in order to obtain a true reflection of the workload.

We accept that the workload figures may include a small proportion of duplicated data, for example if a diagnostic skin biopsy was followed by subsequent excision at a later date. It is also possible that some data have not been captured. However, it is current practice that, where possible, patients with an NMSC who are to receive radiotherapy or topical therapy will have a biopsy in advance. Thus these data will have been captured by the NICR. In complex cases, such as Mohs' micrographic surgery, involving multiple specimens, the data 
generated are captured as one event from the summary report. Therefore, overall we feel that the workload data are a fair reflection of the true numbers of NMSCs encountered in clinical practice in Northern Ireland.

The management of a patient with skin cancer involves many disciplines, including dermatology, plastic surgery, pathology, oncology, radiology and administration departments. The increase in workload shown by the above figures will have a significant impact on many members of the multiprofessional skin cancer team, although this is difficult to quantify. It will require adequate financial planning and increased resources in order to cope with such demand in the future. The volume of suspected and actual skin cancer cases being referred to dermatology departments impacts significantly on the management of other chronic skin diseases, largely due to the pressure on clinic appointments and the fact that skin cancers are usually prioritized as urgent.

A recent study attempted to estimate the financial cost of skin cancer to the National Health Service (NHS) in England in 2002. ${ }^{20}$ NHS costs were calculated by combining published data on health service use by patients with skin cancer with published data on the unit cost of services. The total cost of skin cancer to the NHS was calculated in excess of $£ 71$ million. Although considerable, this represents only $4 \%$ of total NHS expenditure on all cancers, even though skin cancer accounts for at least $20 \%$ of all cases of cancer. ${ }^{21}$ It was postulated that the cost of managing the large number of patients with skin cancer is kept to a minimum because of efficient, often curative, surgery which can be carried out on an outpatient basis, often avoiding the need for expensive inpatient care.

In conclusion, in view of the data presented it is clear that management of NMSC and MM will impose significant demands on dermatology services and other related specialties in the years ahead. The ageing population in the U.K. will inevitably contribute to a further increase in skin cancer workload. The number of individuals aged 60 years and over is set to rise by more than half by 2030 and it is in this age group that $80 \%$ of all NMSCs occur. ${ }^{22}$ This will not only affect dermatologists but will impact on the entire multidisciplinary team. Future planning, in terms of manpower and resources, will prove essential if we are to remain in a position to manage patients with these malignant tumours appropriately, while not compromising the management of other chronic dermatological diseases.

\section{References}

1 Stang A, Stegmaier C, Jockel KH. Non-melanoma skin cancer in the Federal State of Saarland, Germany, 1995-1999. Br J Cancer 2003; 89:1205-8.
2 de Vries E, van de Poll-Franse LV, Louwman WJ et al. Predictions of skin cancer incidence in the Netherlands up to 2015. Br J Dermatol 2005; 152:481-8.

3 Diepgen TL, Mahler V. The epidemiology of skin cancer. Br J Dermatol 2002; 146 (Suppl. 61):1-6.

4 Lucke TW, Hole DJ, MacKie RM. An audit of the completeness of non-melanoma skin cancer registration in Greater Glasgow. Br J Dermatol 1997; 137:761-3.

5 National Institute for Health and Clinical Excellence. http:// www.nice.org.uk/ (last accessed 23 February 2007).

6 Goodwin RG, Holme SA, Roberts DL. Variations in registration of skin cancer in the United Kingdom. Clin Exp Dermatol 2004; 29:328-30.

7 Davies T, Page M, Coebergh W. ENCR Recommendations. Non-Melanoma Skin Cancers. http://www.encr.com.fr/skinrecs.pdf (last accessed 23 February 2007)

8 U.S. National Cancer Institute. Joinpoint Regression Program (version 2.7), 2003. http://srab.cancer.gov/joinpoint/ (last accessed 23 February 2007).

9 Kim HJ, Fay MP, Feuer EJ, Midthune DN. Permutation tests for joinpoint regression with applications to cancer rates. Stat Med 2000; 19:335-51.

10 Noble M, Smith G, Wright G et al. Measures of Deprivation in Northern Ireland. 2001. Northern Ireland Statistical Research Agency (NISRA) Occasional Paper No. 18.

11 Northern Ireland Statistics and Research Agency. http://www.nisra. gov.uk/ (last accessed 23 February 2007).

12 Office for National Statistics. http://www.statistics.gov.uk/ (last accessed 23 February 2007).

13 MacKie RM, Bray CA, Hole DJ et al. Incidence of and survival from malignant melanoma in Scotland: an epidemiological study. Lancet 2002; 360:587-91.

14 Katalinic A, Kunze U, Schafer T. Epidemiology of cutaneous melanoma and non-melanoma skin cancer in Schleswig-Holstein, Germany: incidence, clinical subtypes, tumour stages and localization (epidemiology of skin cancer). Br J Dermatol 2003; 149:1200-6.

15 de Vries E, Louwman M, Bastiaens $M$ et al. Rapid and continuous increases in incidence rates of basal cell carcinoma in the southeast Netherlands since 1973. J Invest Dermatol 2004; 123:634-8.

16 Miller DL, Weinstock MA. Nonmelanoma skin cancer in the United States: incidence. J Am Acad Dermatol 1994; 30:774-8.

17 MacKie RM, Hole DJ. Incidence and thickness of primary tumours and survival of patients with cutaneous malignant melanoma in relation to socioeconomic status. BMJ 1996; 312:1125-8.

18 Melia J, Ellman R, Chamberlain J. Meeting the Health of the Nation target for skin cancer: problems with tackling prevention and monitoring trends. J Public Health Med 1994; 16:225-32.

19 McLoone NM, Middleton RJ, Gavin AT et al. Audit of basal cell carcinoma: registration practice. Br J Dermatol 2003; 148:371 (Letter).

20 Morris S, Cox B, Bosanquet N. Cost of Skin Cancer in England. Imperial College London: Tanaka Business School, 2005.

21 Bosanquet N, Sikora K. The economics of cancer care in the UK. Lancet Oncol 2004; 5:568-74.

22 Diffey BL, Langtry JAA. Skin cancer and the ageing population. Br J Dermatol 2005; 153:679-80. 